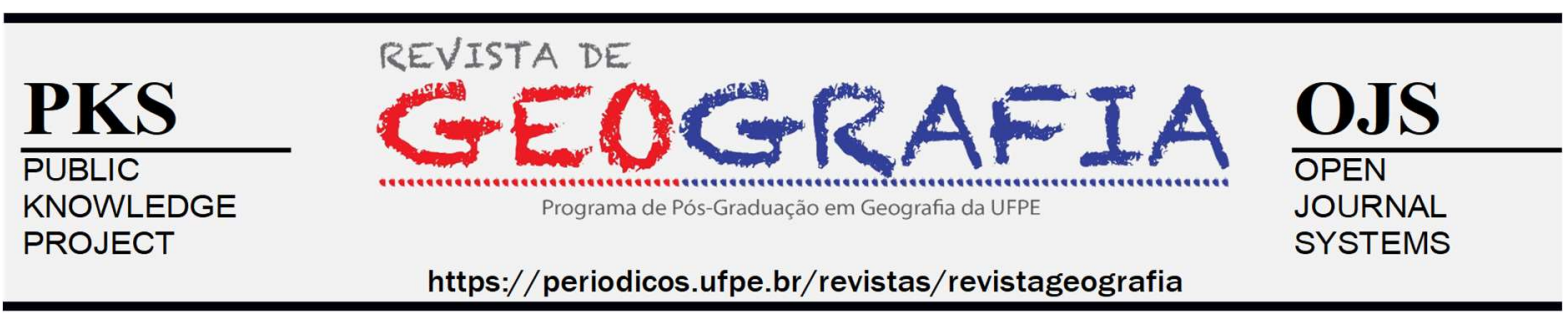

NOTAS DE PESQUISA

\title{
TERRA, TRABALHO, CONFLITO: PRECARIZAÇÃO E DESORDEM TERRITORIAL INDIGENISTA NO PERÍODO (2007 A 2015)
}

\author{
Sandoval dos Santos Amparo ${ }^{1}$ \\ ${ }^{1}$ Universidade do Estado do Pará. Doutor em Geografia, UFF² Universidade Federal de Sergipe/Programa de Pós \\ Graduação de Geografia.E-mail: sanamparo@gmail.com \\ Artigo recebido em 28/03/2020 e aceito em 16/06/2020 \\ Resumo: Este trabalho foi escrito originalmente entre fevereiro e março 2016, como atividade do Seminário de \\ Releitura Crítica do Projeto de Tese apresentado ao Programa de Pesquisa em Geografia da Universidade Federal \\ Fluminense. Aborda a precarização territorial contemporânea a partir de três categorias teóricas: terra, trabalho e \\ conflito, tendo por chão empírico a desordem territorial indigenista no período 2007-2015. Palavras-chave: Trabalho, \\ precarização, indigenismo, arranjo espacial, território.
}

\section{APRESENTAÇÃO}

Não há limites para a precarização. (Graça Druck, 2011)

Em função das fortes referências a este trabalho constantes na Tese de cujo processo estas ideias participaram decisivamente, busquei tornar público este texto, primeiro por compartilhamento junto aos colegas do IX Simpósio Português de Sociologia, realizado em Algarve - Faro, ao qual não pude comparecer e, em seguida, em meio digital, via redes sociais, a pedido de alguns pesquisadores mais próximos e ainda em seu formato original de atividade acadêmica. Agora, apresento-o na forma de um artigo, por acreditar na relevância de alguns dos temas aqui abordados, enfatizando ainda as categorias terra, trabalho e conflito para encetar o debate sobre a desordem territorial indigenista e tornar possível o diálogo entre geógrafos e a etnógrafos pela via da territorialização, abrindo-se ainda à sociologia do trabalho, pela análise da atu-ação indigenista. 
As reflexões aqui suscitadas, sobre a desordem territorial indigenista, se inserem no contexto da precarização territorial contemporânea e emergem desde o chamado "mundo do Trabalho" para assombrar o cotidiano da sociedade e, no caso indigenista, estabelecer sua "nova" ordem territorial, na forma do arranjo espacial indigenista. Objeto de análise que gostaria de tomar seja a partir das ideias autores como João Pacheco de Oliveira, Antônio Carlos de Souza Lima, na antropologia; ou ainda de Ruy Moreira e Rogério Haesbaert, na Geografia, geógrafos cujas interpretações da "realidade" geográfica repercutem as ideias de filósofos como Marx, Lefebvre, Foucault, Edgar Morin, dentre outros. Ainda assim, no entanto, saberes disciplinados.

Mas ao mesmo tempo, nem separado e nem com menor importância, este trabalho remete aos saberes do cotidiano e da (geralmente mistificada) ação indigenista.

\section{Três aspectos do indigenismo}

Para Antônio Carlos de Souza Lima (1995) o indigenismo apresenta três aspectos simultâneos, que iluminam o contexto indigenista:

a) Pensamento indigenista, isto é, a reflexão política e teórica sobre o processo histórico de dominação colonial e republicano, objeto de interesse interdisciplinar, e que ao mesmo tempo se abre aos horizontes do campo, vide a forte aceitação do trabalho de sertanistas e indigenistas escritores, alguns deles Best Sellers de grandes editoras, como os irmãos Villas-Boas, ou ainda Fernando Schiavini e Txai Terri Aquino, dentre outros. Participam também destes debates, alguns indígenas autores de textos e pesquisas, a grande maioria deles apresentando uma abordagem bastante característica do pensamento ameríndio. Destaco, aqui, alguns trabalhos que chegaram a mim, dentre muitos outros: os professores indígenas Bep Punu Kayapó (2019), sobre a importância de registrar a língua Kayapó ou o de Roni Paresi Halit--Hanã, sobre a arte da pintura e da expressão artística e poética Haliti-Hanã,além de Daniel Munduruku e Ailton Krenak;

b) A política indigenista, isto é, o arranjo político-ideológico que orienta a política pública direcionada aos sujeitos indígenas, o "agenciamento" indigenista, cuja mudança com o tempo repercute territorialmente.

c) A ação indigenista, fundada originalmente no preação (laica) / tutela (cristã), sendo estas as duas ações práticas realizadas junto aos índios a partir do século XVI nas Américas, vide terceiro tomo a tese ou a síntese organizada pelos antropólogos referidos. A estas ideias acrescentaira, a face atual do neocolonialismo multiculturalista, o projetismo - os projetos de 
"etnodesenvolvimento", categoria-balaio que abriga todos os gatos imagináveis, alguns dignos outros nem tanto e cujos problemas são apontados por autores como João Pacheco de Oliveira (2008) e Hectór-Diaz Polanco (2003), principalmente.

Embora menor valor se-lhe atribua por muitos pesquisadores, a ação indigenista comporta uma multiplicidade de sujeitos que, de algum modo, coexistem no espaço da aldeia, por exemplo:

i) agentes indigenistas como motoristas, pilotos de barco e voadeira, por assim dizer, profissionais do campo, sem os quais a grande maioria das atividades indigenistas não se realizaria e que, no entanto, são tomados sujeitos menores pelos geógrafos que, enfatizando o conflito recusam a enxergar $o$ trabalho enquanto categoria e a precarização que dele decorre na construção do cotidiano indigenista.

ii) na mesma direção, do trabalho, temos madeireiros, garimpeiros, ongueiros, assessores políticos, etc. os sujeitos descritos por Casaldaglia em seu famoso texto de $1971^{1}$; ou, ainda os neo-amazônidas, colonos do sul que, buscaram na Amazônia a disponibilidade de terras inexistente em sua região. Favoreceu este processo implantação de infraestruturas, sobretudo estradas e grandes projetos, que por meio de uma combinação entre acumulação primitiva e renda diferencial da terra, torna possível o processo de extrativismo mineral e desenvolvimento na Amazônia. Como mostrou Porto-Gonçalves (2003), este processo intensifica-se com o modelo rodoviarista de uso do território ("estradaterra-firme-subsolo"), resultante do processo de modernização conservadora implantado na região amazônica pelo regime civil-militar a partir dos anos 1960, a que se acrescenta, mais recentemente, o extrativismo mineral e as hidrelétricas.

Estas são, assim, as matrizes de realidade que impactam direta ou indiretamente o cotidiano na aldeia, e que não podem ser desconsideradas. Tão importante quanto terra e conflito, o trabalho emerge como categoria analítica da realidade indigenista e, de maneira ambígua, como orientação da própria política pública republicana. Além disso, o trabalho ganha relevância com o contexto contemporâneo de sua extinção, como demonstra o Prof. Ricardo Antunes ${ }^{2}$.

\footnotetext{
${ }^{1}$ Apud Autor, 2019.

2 ANTUNES, 2008.
} 
As leituras de textos e as reflexões sobre terra, trabalho e conflito são, assim, cruciais para as leituras do humano no universo indigenista. Com os sociólogos do trabalho, aprende-se sobre o indigenismo em termos de situ-ação (ação situada), algo coerente com minha implicação particular ao tema: vítima de assédio moral, transferido compulsoriamente, preterido para cargos de confiança mesmo com o currículo favorável, etc., em função da interseccionalidade de preconceitos, e, além de tudo, crítico do modelo hegemônico do novo indigenismo. Tudo isto vinha à tona em termos de precarização territorial e esta era a paisagem indigenista no período entre 2007 e 2015, principalmente a partir de 2009.

Se terra e conflito são categorias fortemente discutidas pelos geógrafos indigenistas; o trabalho, no entanto, parece ter lugar apenas em contextos marxistas. Gostaria com este texto de abordar esta categoria, aliando-a às duas categorias já mencionadas, para em conjunto, constituir a perspectiva de território indigenista em que se baseia este ensaio.

\section{Do objeto de análise ao sujeito de pesquisa: da implicação teórica e geobiografia}

A necessidade de investigar esse cotidiano indigenista e a fecundidade teórica de registrar seus chãos levou-me à leitura dos autores citados, a fim de compreender as questões que me inquietavam relativas à desordem territorial indigenista, sejam:

a) As várias formas de integração, orientação e esforços da política indigenista para o trabalho indígena, como o Etnodesenvolvimento e/ou ideologia do trabalho, esta última, fortemente preconceituosa, parece inspirada na máxima anacrônica da indolência indígena, algo tão real quanto os mitos geográficos da "terra devoluta" e do "sertão desabitado", ambos estratégias discursivas utilizadas para a territorialização colonial e, depois, republicana.

b) A degradação do trabalho indigenista e a precarização do indigenismo, por mim vivenciada, em nome de um novo que em sua estratégia, lançava mão da mística e da misoginia, para legitimar a atuação profissional degradante e arriscada. Como porta de abertura para este debate, o fato de que ô Brasil é um dos países mais perigosos do mundo para a atuação no combate aos crimes ambientaiS. Porto Gonçalves \& Haesbaert, 2006).

O debate sobre a precarização territorial contemporânea (desde as aldeias), começa a se esboçar na Geografia com o forte impacto de autores como David Harvey nos EUA ou Milton 
Santos no Brasil. Mas é com a obra $O$ mito da desterritorialização, do Prof. Rogério Haesbaert, que estas ideias parecem ganhar corpo, em grande parte porque este livro articula ideias de vários escritos anteriores deste autor, fortemente difundidos pelas Revistas de Geografia e Ciências Sociais e que impactaram os platôs e superfícies de emergência teórica da geografia humana brasileira e latinoamericana neste início de milênio.

As ideias de Haesbaert, deste modo, fecundam em questões colocadas por Valter Carmo Cruz, relativas à implicação entre sujeito e objeto desta análise. Busco responder às provocações de Valter Carmo Cruz, sobre os sujeitos que animam e dão vida ao espaço indigenista e sua desordem territorial, além de suas já conhecidas interrogações acerca da diversidade das formas territoriais. Procurei ir ainda mais longe com a tese, através do perspectivismo geográfico, paradigma através do qual busco registrar o esboço do espaço ameríndio e de sua ordem cósmica, a cosmopolitica (Amparo, 2019).

Se a res contemporânea - o mundo e sua ordem - se apresenta como desordem e precarização territorial; o sujeito será, com efeito, como o sujeito múltiplo Moriniano, ao mesmo tempo faber e lúdico, poético e prosaico,etc.. ao mesmo tempo moderno e precário. Mas quais sujeitos poderiam, objetivamente, ser investigados de maneira coerente, no contexto de um curso de doutoramento e de minha geo-biografia particular no contexto da Geografia brasileira, primeiro migrante nordestino no RJ, em seguida como estudante de Geografia da UFF, depois como geógrafo da FUNAI, e em seguida (desde 2015), , como professor de Geografia Humana.

A incerteza e a determinação me fazem, assim, remeter a eméritos físicos conhecidos, (como Prigogini ou Heisenberg) para com eles, por fim, aderir - ainda que provisoriamente - ao abandono da coerência, adotando em seu lugar o colapso por representação e/ou a decoerência, como pode-se notar na tese de doutoramento. É que como mostra Butler (2016), todo relato é insuficiente. Há um total conflito entre mundo e representação, e com a política indigenista não é de outro modo. Esta é a origem da desordem e da precarização. E, no entanto, toda desordem é criadora, como sabemos.

Partindo desta indagação geobiográfica, defini naquele momento um escopo das relações entre fenômenos que tomei por objeto e chamei, então, de precarização territorial contemporânea, nos termos em que será aqui mencionado, e que na tese é tratada em particular no quarto tomo. Ditas estas palavras, contemporaneizadoras, passaram-se quase 4 anos intensos entre escrita e publicação, tentarei ser leal ao trabalho apresentado em 2016 e e não deformá-lo com reflexões posteriores, afim de manter a relevância de suas próprias ideias. Os conceitos que 
aqui proponho: terra, trabalho e conflito, em conjunto, devem ser vistos como uma abordagem possível deste universo de sujeitos, vistos desde seus próprios processos de territorialização/desterritorialização e de suas próprias categorias de interpretação do mundo.

\section{O período 2007-2015 e o banquete "Iulista" do Consumo, desordem e precarização}

Tendo por referência o período entre 2007-2015, os aspectos de caos sistêmico e precarização aqui apontados consistiam apenas na transição em direção ao plasma incendiário que sucedeu, com o impedimento da Presidente Dilma Roussef (2016), e a ascensão do Bolsonarismo (2018), ambos consistindo em claros acenos ao capital financeiro internacional, com a receita já conhecida da redução do Estado e dos direitos dos trabalhadores e também aos indígenas e as chamadas comunidades tradicionais.

Segundo Henry Lefebvre, onde estiveram no poder, os projetos de esquerda consistiram em regimes orientados para o consumo e o desenvolvimentismo, a tal ponto, que o filósofo e sociólogo francês afirmava que a esquerda queria "conduzir a classe trabalhadora ao banquete do Capital"3. Em diversos outros momentos, o próprio Lefebvre argumenta que a inclusão das classes trabalhadoras neste banquete não se faz, contemporaneamente, pela revolução, mas pelo consumo. $\mathrm{O}$ direito à cidade é, em suma, o direito ao consumo ${ }^{4}$. E não foi outro o projeto posto em prática pelos governos petistas no Brasil, com relativo sucesso, ainda que o projeto tenha sido sabotado muitas vezes no decurso da história e da geografia recentes.

A ampliação dos conflitos indigenistas, sobretudo a partir do ano de 2007, em grande parte decorre do conjunto de medidas políticas internas tomadas pelo Governo Federal no contexto político do que Singer chamava, à época, de Lulismo (Singer, 2012). A guinada "lulista", conforme este autor, correspondia à inversão política que se estabeleceu com o avanço de políticas populistas no Governo Petista, que passaram a predominar a partir da aproximação de Lula dos políticos e eleitores de perfil mais moderado e conservador, fazendo com que viesse a ser alterada a plataforma social que viabiliza a "governança" do país: de ex-líder sindical e referência do movimento dos trabalhadores, Lula se aproxima de ícones das oligarquias e do grande capital.

O Lulismo, em suma, representava uma inédita e histórica aliança entre Capital e Trabalho no Brasil, resultando em expansão do consumo e das infra-estruturas territoriais que

\footnotetext{
${ }^{3}$ LEFEBVRE, 1991, p. 26.

${ }^{4}$ LEFEBVRE, 2001, p. 92. Em especial o capítulo “Teses sobre a cidade e a urbanização” (p. 92-101).
} 
sobre as quais este processo processa seu devir: expansão do consumo, do extrativismo mineral, "modernização" do conflito no campo: onde eram sem-terra x latifundiários, agora são comunidades tradicionais x empresas... é o que nos mostra os Cadernos de Conflitos no Campo da Comissão Pastoral da Terra para o período. Longe de combater o latifúndio, o governo petista teve uma média inferior de assentamentos, em relação aos dois Governos de Fernando Henrique Cardoso, como nos mostram eméritos pesquisadores. Longe da "ameaça" que representava para o modelo político-econômico, portanto, o Governo Lula priorizou os chamados direitos sociais, na prática, por meio da expansão do consumo, como insistentemente costuma afirmar o prisioneiro ex-Presidente Lula, gigante político que emergiu com o processo histórico-geográfico recente, sobretudo pelos bons resultados econômicos de seus Governos.

Assim, o Governo Lula este comprometido com a manutenção da ordem social burguesa e do (neo)desenvolvimentismo, simbolizados pelo avanço de políticas que beneficiavam setores "produtivos" (como o agronegócio, o industrial e o hidrelétrico) e especulativos (como o setor imobiliário e, sobretudo, o financeiro), aliado às políticas de renda mínima e crédito, que favoreceram a expansão do consumo nas classes inferiores da sociedade. Concorreu ainda para a expansão do consumo no governo Lula, e inclusive nas aldeias, a expansão dos "direitos sociais", que incluíam da casa própria à ampliação de vagas nas universidades (no caso da FUNAI, a reestruturação da instituição em 2009 consolida esta política com a criação de uma Coordenação de Direitos Sociais Indígenas).

Com efeito, abdicando de pautas como a reforma agrária e a reforma urbana, o governo Lula não enfrentou dificuldades em lidar e incorporar os processos de precarização do trabalho à lógica produtivista e econométrica de sua gestão. Com isso, a própria administração, em que pese a expansão do número de servidores públicos durante o período, passou também a ela a operar por meio de processos de precarização do trabalho, como contratos diferenciados para a realização das mesmas atividades, práticas de assédio moral, ou ainda, transferências compulsórias, etc.. Sendo vista por muitos servidores como ação fraterna e passional, a também esta mística é apropriada pela precarização, assim, muitos servidores acabam viajando para as terras indígenas em condições extraordinárias, tendo que investir seus próprios, para em muitos casos, jamais receberem suas diárias devidas, o que, no entanto, acontece apenas a alguns.

Tudo isto repercute de maneira significativa no arranjo espacial, por meio das espacializações impostas pela expansão do consumo e pela significa transformação da estrutura social e econômica das sociedades indígenas e suas terras, impactadas pela intensificação 
crescente dos fluxos de territorialização, que afeta não apenas suas terras, mas suas próprias vidas. Tomo aqui o termo "espacialização" no sentido que lhe é atribuído por Milton Santos, ou seja:

um momento da inserção territorial dos processos sociais (...), é sempre o presente, um presente fugindo.... A espacialização não é o resultado do movimento da sociedade, porque depende do espaço para se realizar. No seu movimento, em busca incessante de geografização, a sociedade está subordinada à lei do espaço existente. ${ }^{5}$

Com efeito, pode-se também definir a espacialidade como "um momento das relações sociais geografizadas, o momento da incidencia da sociedade sobre um determinado arranjo espacial" ${ }^{\prime \prime}$.

\section{A crise do arranjo espacial indigenista: desordem, multiterritorialidade, precarização}

A partir do quadro teórico e empírico acima tratado tentarei, ao analisar a precarização do indigenismo no período de 2007-2015 - um período sob Governos Petistas -, sustentar a tese de que a precarização do indigenismo se insere no contexto de ruptura com o arranjo espacial, o indigenismo clássico, implicando em recuos de cidadania para os sujeitos sociais envolvidos (indígenas e indigenistas). Esta ruptura se dá pela apropriação das instâncias socioeconômica, com a cooptação econômica de indígenas e indigenistas; político-jurídico, por meio de atos administrativos com efeito prático (na vida dos dos sujeitos) ${ }^{7}$; e, instância cultural-ideológico, através de discursos e representações a serem propagandeadas pelos arautos do "Novo Indigenismo" (em sua maioria estes arautos são remunerados), investigando os recuos de cidadania decorrentes da desordem territorial que pesam sobre os sujeitos sociais pela ruptura do arranjo espacial do indigenismo rondoniano ${ }^{8}$, desde o ponto de vista dos que atuam sobre ela e nela possuíam suas "bases territoriais" de atuação profissional, aprofundando os efeitos da precarização no que diz respeito à precarização das condições de trabalho, resultando em adoecimentos e afastamentos do trabalho. Isto se fará observando o avanço da precarização e suas representações nos espaços percebido, vivido e concebido, portanto, por meio das representações do espaço.

Pelo que investigamos até agora, parece que se aceita atualmente, entre os sociólogos, que a precarização surge no ambiente de trabalho, de onde se expande para o tecido social,

\footnotetext{
${ }^{5}$ Santos, 2003:80-81.

${ }^{6}$ Santos, 2003, idem.

${ }^{7}$ Centenas de servidores, dentre eles o próprio autor, foram submetidos a transferências compulsórias e processos administrativos persecutórios, criando um clima de constante instabilidade no espaço de trabalho indigenista.

8 Para referências sobre o indigenismo rondoniano ver Lima, 1995 e GOMES, M. (apud Amparo, 2019b).
} 
intervindo nas relações familiares, na segurança financeira e nas relações de confiança entre as pessoas, todas características atuais do trabalho no contexto da chamada "acumulação flexível", cuja racionalidade corresponde ao esfacelamento do Estado de Bem Estar social no mundo desenvolvido, e no seu aborto nos países colonizadores, nos quais este modelo ainda não havia concretizado.

Para Kallemberg, "o trabalho precário tem consequências de longo alcance, atravessando muitas áreas que preocupam cientistas sociais, bem como trabalhadores e suas famílias, governos e empresas". Para a autora:

Isso criou insegurança para muitos, e afeta de modo difuso e amplo não só a natureza do trabalho, os locais de trabalho e a experiência dos trabalhadores, mas também muitos aspectos individuais (estresse, educação) e sociais (família, comunidade) não relacionados ao trabalho, bem como a instabilidade política. Por isso é muito importante entendermos os novos arranjos dos locais de trabalho que geram a precarização e a insegurança ${ }^{9}$.

A ruptura do indigenismo clássico se dá num momento de franca expansão das espacializações neodesenvolvimentistas em direção às terras e territórios indígenas, com a implantação de hidrelétricas, projetos de extração mineral, duplicação de estradas, gasodutos, transposições de rios, etc ${ }^{10}$. Neste cenário de desarticulação institucional, a FUNAI, o principal órgão indigenista do Estado brasileiro, acaba por ter uma atuação tímida e limitada em defesa dos direitos dos povos indígenas ${ }^{11}$, seu público-alvo (muitas vezes atuando contra o interesse destes, como nos casos de Belo Monte, Aldeia Maracanã e Santuário Sagrado dos Pajés), enquanto atravessa uma grave crise interna e de valores, com ascensão de casos de adoecimento de servidores por razões laborais, num contexto da precarização generalizada das condições de trabalho (assédio moral, perseguições internas, jornadas de trabalho extenuantes e em condições análogas às do trabalho escravo ${ }^{12}$, redução da confiança e da amistosidade no ambiente de trabalho, cumprimento de direitos trabalhistas apenas para determinados servidores, isso tudo somado à conflitividade inerente à atuação profissional indigenista $)^{13}$. Por meio da ruptura com o arranjo espacial anterior amplia-se o padrão de conflitividade da política indigenista atual, cujas

\footnotetext{
${ }^{9}$ Kallemberg, 2009:22.

${ }^{10}$ Ver dados da CPT 2015.

11 "Demarcação de terras não avança no Governo Dilma", Opinião \& Notícia, 11 de agosto de 2015.

12 "Ver matéria: "União e FUNAI são condenadas por submeter trabalhadores a trabalho degradante", Portal Amazônia Web, 2 de agosto de 2013.

13 Acrescente-se aqui o falocentrismo, a saga do indigenista "macho", ou os batismos nos quais o indigenista "tem que provar que é homem".
} 
marcas principais são ascensão da precarização ${ }^{14}$ e a incapacidade de gerir e solucionar conflitos duradouros $^{15}$, estes impactando os sujeitos sociais por, se iniciando no ambiente de trabalho indigenista - sedes da FUNAI, pontos de apoio e Terras Indígenas - expandirem-se para o cotidiano das pessoas, territorializando ${ }^{16}$ os espaços sociais de indígenas e indigenistas, por meio de assédios, tensões, medo, insegurança e adoecimentos ${ }^{17}$, provocados pela forte tensão e a iminência de tragédias ${ }^{18}$.

\section{O arranjo espacial do indigenismo clássico: brevíssima arqueologia e genealogia}

A ação indigenista remonta aos primórdios da colonização, já que, chegando no continente a ser desbravado o colonizador estabeleceu violentas relações com os que aqui viviam, ignorando suas racionalidades e mesmo a humanidade dos índios, afim de instalarem uma ordem colonial eurocêntrica. Esta ordem se funda, desde o início, nas diversas formas de violência conhecidas de ordem física (assassinatos de homens e violência sexual contra mulheres) e psicológica (imposição de novos credos e línguas, perseguição de lideranças políticas, etc.).

Até o século XVIII os índios estiveram abandonados à dominação violenta e "legítima" dos bandeirantes ou á dominação religiosa por meio da catequese. Apenas no século XVIII é que se estabelece um Diretório de Índios, em 1750, que seria extinto antes mesmo de completar meio século de existência, mantendo-se, porém, a figura do cargo "diretor de índio", ocupado

\footnotetext{
14 “Índios protestam contra Decreto que reestrutura a FUNAI", Estado de São Paulo, 6 de janeiro de 2010;"Índios realizam protesto em todo o Brasil contra reestruturação da FUNAI", Folha de Sâo Paulo, 2 de fevereiro de 2010.

15 "FUNAI nega omissão em conflito no sul do Amazonas", Portal $A$ Crítica, 8 de janeiro de 2014.

${ }^{16}$ Ver matéria: "FUNAI investigará desaparecidos na reserva Tenharim", Portal Amazônia Real, 26 de dezembro de 2013.

17 "Protesto de servidores da FUNAI marcam o dia do índio", Página de Notícias do SINDSEP-SP, 21 de abril de 2015.

${ }^{18}$ Caso emblemático da crise do arranjo espacial indigenista e sua desordem, o conflito ocorrido em pleno natal de 2013, quando três homens não-indígenas desapareceram na Terra indígena Tenharim-Marmelos. A FUNAI apenas se pronunciou sobre os desaparecimentos por meio de nota fria e descomprometida. Insulflados por agentes políticos e econômicos contrários aos interesses indígenas, a população revoltada incendiou a sede do órgão, seus barcos e viaturas. A revolta se intensificou após manifestação bastante infeliz do Sr. Carlos Travassos, então Coordenador de Índios Isolados,na qual afirmara que "só existem crimes quando tem corpos".,, fala imediatamente associada à fala do ex-goleiro Bruno, então atleta do Flamengo, que alguns anos antes havia assassinado a modelo Elisa Samúdio, com a ajuda de comparsas, dando fim a seus vestígios mortais. Bruno proferiu exatamente a mesma declaração. Após estas reações, a FUNAI debruçou-se de maneira mais séria sobre o conflito e emitiu então, uma segunda nota, no dia 28 de dezembro de 2013, reconhecendo a gravidade dos fatos e mostrando-se disposta a colaborar com as investigações iniciadas pela Polícia Federal. 55 dias após o início dos conflitos, a Polícia Federal localizou os três corpos no interior da Terra Indígena e o processo segue em segredo de justiça, tendo havido a prisão de cinco indígenas por envolvimento no assassinado dos mesmos, e indícios da participação de diversos outros, bem como de não indígenas, num crime que teria sido motivado por vingança pelo suposto assassinato do Cacique Ivan Tenharim. No enntanto, a perícia médica e policial apontam que Ivanm Tenharim foi a óbito em decorrência de um acidente de motocicleta provocado por alcoolismo.
} 
geralmente por padres, militares ou bandeirantes. Não há neste período ruptura com o modelo anterior, senão que a sua institucionalização. Durante todo o século XIX a política indigenista será marcada pelo "vácuo" jurídico-político. Os indígenas, assim como os negros, ficam de fora da Lei de Terras de 1850 (Faria, 2008), já que esta vem legitimar a grande propriedade rural no Brasil e contemplar os imigrantes recém-chegados da Europa, estes tomados como parte do arranjo ideológico ainda hoje hegemônico, conformando o modo de produção escravista-colonial e em seguida, o modo de produção moderno-plantacionista-latifundiário, efetivado com o "branqueamento" da população.

É já no século XX, que se cria o Serviço de Proteção ao Índio (e Localização dos Trabalhadores Nacionais), com um notório caráter de integração destes povos - em verdade nações - à "comunhão nacional”, ou seja, ao sistema de relações sociais estabelecidos pelo avanço do capitalismo dependente no Brasil. Embora tenha vigorado ao longo de todo o século XX, arranjo político-jurídico integracionista, cujo principal idealizador é o Marechal do Exército Cândido Mariano Rondon (ele próprio indígena miscigenado) se estabelece tardiamente, com a lei 6001/1973, estabelecido de maneira arbitrária, durante o período militar, possuindo forte conotação nacionalista. O Estatuto do Índio em seus artigos $3^{\circ}$ e $4^{\circ}$ chega a estabelecer uma classificação dos indígenas conforme seus diferentes "graus" de integração à "comunhão nacional".

Art. $3^{\circ}$ Para os efeitos de lei, ficam estabelecidas as definições a seguir discriminadas:
I - Índio ou Silvícola - É todo indivíduo de origem e ascendência pré-colombiana que
se identifica e é identificado como pertencente a um grupo étnico cujas características
culturais o distinguem da sociedade nacional; II - Comunidade Indígena ou Grupo
Tribal - É um conjunto de famílias ou comunidades índias, quer vivendo em estado de
completo isolamento em relação aos outros setores da comunhão nacional, quer em
contatos intermitentes ou permanentes, sem contudo estarem neles integrados. Art $4^{\circ}$
Os índios são considerados: I - Isolados - Quando vivem em grupos desconhecidos ou
de que se possuem poucos e vagos informes através de contatos eventuais com
elementos da comunhão nacional; II - Em vias de integração - Quando, em contato
intermitente ou permanente com grupos estranhos, conservam menor ou maior parte das
condições de sua vida nativa, mas aceitam algumas práticas e modos de existência
comuns aos demais setores da comunhão nacional, da qual vão necessitando cada vez
mais para o próprio sustento; III - Integrados - Quando incorporados à comunhão
nacional e reconhecidos no pleno exercício dos direitos civis, ainda que conservem
usos, costumes e tradições característicos da sua cultura.

De certo modo, este paradigma não desapareceu por completo do horizonte indigenista brasileiro. No entanto, esta perspectiva se aproxima mais do indigenismo rondoniano, hegemônico durante mais de 3/4 do século XX (mais precisamente, até a Constituição Federal de 
1988), cuja característica principal é o integracionismo, consituindo assim, um tipo de indigenismo "clássico".

As características gerais do arranjo espacial indigenista clássico são: a) Delimitação de áreas indígenas (zonas), visando à “contenção" dos indígenas e à integração destes por meio da agricultura (Lima \& Oliveira, 1990); b) Redes de Postos Indígenas, Postos de Vigilância e Frentes de Atração (para os casos isolados) no interior destas áreas; (pontos de apoio operacional); c) Criação de Unidades Regionais da FUNAI, pontos de apoio logístico, comandadas desde a sede, sediada primeiro no Rio de Janeiro (extinto SPI) e depois em Brasília (redes).

Tal arranjo nada possui de ingênuo. Trata-se de uma lógica ordenadora bem definida, cunhadas a partir da instância socioeconômica (reprodução da integração [dependente] do Brasil ao capital monopolista internacional), da instância político-jurídica (estabelecimento de uma “ordem" indigenista, necessária para a pactuação de acordos que visavam, principalmente, a demarcação de terras) e ideológica (propalados desde o cristianismo e de noções como "do valor social do trabalho", mas também pela internalização pelos próprios indígenas de preconceitos que induzem a hábitos civilizatórios, pela negação da própria identidade). A instância ideológica viabiliza que ainda em dias atuais, se invista recursos públicos em ferramentas e combustíveis, distribuídos gratuitamente nas aldeias, em raros casos fugindo do esquema paternalista. $\mathrm{O}$ arranjo espacial do indigenismo tem em sua formação socioeconômica o estímulo ao trabalho, que induzirá concomitantemente à introdução nas aldeias de "extensões do corpo" (ferramentas) e "próteses espaciais" (inscrições territoriais do design territorial indigenista, postos, "granjas" de soja, florestas primárias e revegetadas, perpassamento por estradas, etc.).

\section{O "novo" indigenismo e a nova (des)ordem territorial (2007-2015)}

O arranjo espacial indigenista, como também se fez notar, apresenta uma lógica territorial dupla, porém sincrônica. Assim, as Terras Indígenas ${ }^{19}$ serão unidades territoriais bem delimitadas, portanto zonais; já os postos e as administrações regionais, obedecerão à uma lógica territorial reticular. O indigenismo clássico estabelece sua geograficidade com base em dois modelos de territorialização, já bem definidos por Haesbaert, que são: i) territorialização zonal: sociabilidade controlada dos indígenas num contexto de forte atuação da instância ideológica

\footnotetext{
${ }^{19}$ Há vasta discussão sobre a noção de terra indígena e o fato de raramente constituírem a integridade do que seriam os territórios ancestrais indígenas. Ver Oliveira \& Lima (Orgs.), 1990; Sales (2008) e Amparo (2015).
} 
(estímulo ao trabalho, à integração); ii) territorialização em redes: controle hierárquico das políticas públicas estabelecidas para os territórios zonais, por meio da rede indigenista, composta por unidades operacionais (postos indígenas e de vigilância) unidades administrativas administrações (coordenações regionais, núcleos de apoio locais, situados em pontos estratégicos das regiões onde incidem as TIs. Este arranjo, visa, pois oferecer suporte para as funções administrativas (caso das coordenações e núcleos) e logísticas (postos indígenas e de vigilância, situados em aldeias de maior porte ou em posição estratégica no interior das áreas indígenas).

Mas o Novo Indigenismo era, realmente, novo? Não nos parece. Conforme Haesbaert:

Talvez seja esta a grande novidade da nossa experiência espaço-temporal dita pósmoderna, onde controlar o espaço indispensável à nossa reprodução social não significa (apenas) controlar áreas e definir "fronteiras", mas, sobretudo, viver em redes, onde nossas próprias identificações e referências espaciais e simbólicas são feitas não apenas no enraizamento e na (sempre relativa) estabilidade, mas na própria mobilidade. ${ }^{20}$

Ora, quando tratamos do indigenismo, a mobilidade territorial surge de muitas possibilidades. Primeiramente, ela parece ser a própria lógica territorial predominante de determinados povos indígenas, mesmo antes da chegada do colonizador. Este é o caso, sobretudo, dos povos Jê, cuja dinâmica territorial é bastante conhecida da etnologia e da arqueologia ${ }^{21}$. Destaque-se que não se trata de uma mobilidade aleatória, mas demarcada por determinadas condicionantes socioculturais, sejam elas mitológicas, seja políticas e materiais. Tal situação de migração também é descrita para outros povos. O caso Guarany Mbya foi estudado pela geógrafa Camila Faria, em sua dissertação de mestrado, defendida na USP ${ }^{22}$. Ainda hoje a mobilidade persiste entre muitos povos indígenas, tendo, contudo caráter apenas residual, em função das restrições territoriais impostas aos indígenas com o avanço da territorialização nacional sobre suas terras. O indigenismo clássico, entretanto, em seu processo integracionista, se opõe frontalmente a este modelo de territorialização pautado na mobilidade indígena e lhes impõe a ruptura.

Se o indígena é compelido a fixar-se, a sedentarizar-se, a mobilidade dos agentes indigenistas passa a ser altamente valorizada pela política pública indigenista, característica que

\footnotetext{
${ }^{20}$ Haesbaert, 2013:279.

${ }^{21}$ Os povos "Jê" correspondem às diversas hordas indígenas cujas línguas são associadas a este tronco linguístico. Dentre elas: Kaingáng, Krahô, Kaiapó(Mebengokré), Xavante e Bororo, dentre outros.

${ }^{22}$ FARIA, 2008.
} 
persistirá ainda hoje, com o novo arranjo espacial indigenista; contudo, num quadro completamente diferente do quadro do indigenismo clássico: enquanto este operou uma "estruturação" espacial, por meio da implantação de "próteses" espaciais que davam suporte à atividade, o "novo indigenismo" operou a des-territorialização deste arranjo espacial, por meio de sua precarização.

A precarização, assim, é a crise do arranjo territorial indigenista, e decorre da impossibilidade do exercício pela FUNAI de um "Estado total" nas aldeias como prevê o arranjo de poder. A resultante disto é a crise da aldeia e de seus espaços, produto da relação entre os índios e os regionais.

Com efeito, a precarização afeta o ordenamento indigenista de um modo bastante intenso, mas não desmonta por completo o arranjo espacial anterior, sendo possível constatar continuidades e rupturas em sua estruturação. "O que restou” (resíduo), "o que se desapareceu" e "o que surgiu" desta desordem criadora consiste no atual arranjo espacial indigenista, o que faremos definindo uma periodização clara: o período entre 2007-2015 no Brasil, ao qual está associado a ascensão da precarização imposta pelo "novo indigenismo ${ }^{23}$ ", com implicações, sobretudo, no ambiente de trabalho. O Decreto 7747/2012, que institui a PNGATI - Política Nacional de Geatão Ambiental e Territorial das Terras Indígenas constitui um marco desse processo, pois, se pauta já por uma lógica que atende diretamente ao arranjo ideológico no qual avança a precarização e a terceirização da política indigenista, por meio do repasse de milionários recursos para viabilizar a atuação de ONGs, as quais detinham grande influência política na FUNAI e no Governo e se tornaram arautos do "novo indigenismo", ao mesmo tempo em que busca estabelecer os marcos e o estatuto de um de indigenismo ambientalista contemporâneo.

O novo indigenismo é ambientalista por algumas razões. Primeiro, porque prevalecem no texto da PNGATI, documento referencial do Novo Indigenismo, uma lógica ambientalista em relação à lógica indigenista. Ela acompanha a mudança no paradigma geográfico da sociedade da lógica geomórfica para a lógica biológica, repercutindo um certo holismo de base humboldtiana que toma o humano, ou seja, a lógica indigenista, por superada. Daí seu enfoque na preservação do meio ambiente e no combate ao desmatamento, num paradigma de política e ação ambiental esquizofrênicos quqe gostaria de chamar de ordem plasmática. Seu lado mais

${ }^{23}$ Ver matéria "Omissão da FUNAI pode ter levado a guerra no Vale do Javari”, Carta Capital, 19 de novembro de 2015. 
perverso é a guerra etnicista contra os pobres da Amazônia, corpos agenciados para o garimpo, o desmatamento e a vida nua no sertão com fim.

A des-territorialização do indigenismo clássico traz em sí uma nova e perversa territorialização indigenista, que se insere na conjuntura atual de precarização do trabalho, característica da acumulação flexível, provocando para indígenas e indigenistas, diversos recuos de cidadania e da qualidade de vida. O controle social dos sujeitos envolvidos - índios e indigenistas - é indispensável para a realização deste projeto do indigenismo clássico, o que por fim, representa uma grave ameaça à própria democracia.

\section{As dimensões do precariado e a ação indigenista}

Segundo Sá, “apesar da dificuldade em encontrar uma definição comum e rigorosa de ‘trabalho precário"”, é possível associá-lo às seguintes características:

i) insegurança no emprego; ii) perda de regalias sociais; iii) salários baixos; iv) descontinuidade nos tempos de trabalho. Associamos, assim, o trabalho precário à instabilidade (impossibilidade de programar o futuro - situação dos jovens que ficam até mais tarde em casa dos pais); à incapacidade econômica (impossibilidade de fazer face aos 'riscos sociais' e de assegurar as despesas econômicas do cotidiano - o surgimento dos novos pobres). E à alteração dos ritmos de vida (alteração nos horários de trabalho e da relação trabalho/desemprego). ${ }^{24}$

Tal perspectiva integra o "novo espírito do capitalismo", como propõe Graça Druck, citando Sennet. Bordieu foi um dos primeiros sociólogos a perceber a ascensão do fenômeno da precarização. Ele a define como sendo "um regime político, inscrita num modo de dominação de tipo novo, fundado na instituição de uma situação generalizada e permanente de insegurança, visando a obrigar os trabalhadores à submissão e à aceitação da exploração" (Bordieu apud Druck, 2011:44).

Seguindo Bordieu, Graça Druck aponta que tal conjuntura não se trata de uma exigência econômica, sendo antes,

Produto de uma vontade política e não de uma fatalidade econômica, que seria dada, pela mundialização (...). Esse regime é constituído por vontades (ativas ou passivas) de poderes políticos e, portanto, não pode ser explicada por leis inflexíveis de um regime econômico, mas sim por escolhas orientadas para preservar a dominação cada vez mais completa do trabalho e dos trabalhadores. ${ }^{25}$

\footnotetext{
${ }^{24}$ Sá, 2010:91.

${ }^{25}$ Druck, 2011:44.
} 
Kallemberg define as sete dimensões principais do precariado, cinco das quais diretamente relacionadas a emprego e trabalho:

1. Insegurança do mercado de trabalho (falta de oportunidades); 2. Insegurança do trabalho (proteção inadequada contra perda de emprego ou demissão arbitrária); 3. Insegurança de emprego (inabilidade de continuar em uma ocupação devido à falta de delimitações claras do tipo de atividade a ser executada, bem como das qualificações necessárias para tal); 4. Insegurança do trabalho e saúde (condições precárias de segurança contra acidentes); 5 . Insegurança de reprodução de experiência (falta de acesso à educação básica e treinamento contínuo); 6. Insegurança de renda (renda inadequada, limitada garantia de recebimento e baixa perspectiva remuneratória no médio e longo prazo). 7. Insegurança de representação (negação de direitos individuais e limitação da representação coletiva, por meio de diferentes tipos de perfis e contratos para exercer o mesmo tipo de atividade). ${ }^{26}$

O termo precariedade, segundo Kallemberg, surge com o movimento sindical europeu, quando se iniciou o processo de desmonte do estado de bem estar social nestes países, quando "os trabalhadores europeus se tornaram extremamente vulneráveis em relação ao mercado de trabalho e começaram a se organizar em torno do conceito de precariedade, pois enfrentavam condições de moradia e trabalho sem estabilidade ou segurança"27. Em sua análise, aponta uma característica típica da precarização, que é a sua expansão para além dos locais e expedientes de trabalho, ampliando-se de maneira bastante ampla no contexto social no qual os trabalhadores precários se encontram inseridos. Repercute, assim, na queda da qualidade de vida de maneira bastante generalizada, afetando educação, saúde e moradia, tal qual como tentávamos articular em nosso projeto original, demonstrando que não podia ser coincindência o avanço da precarização habitacional num contexto de forte investimento em grandes projetos de habitação, tal qual o Minha Casa Minha Vida.

Segundo Druck,

Aos nossos olhos, o precariado, isto é, o proletariado precarizado, é formado por aquilo que, excluídos tanto o lupemproletariado quanto a população pauperizada, Marx chamou de 'superpopulação relativa'. A necessidade de definir os limites gerais do precariado nos obriga também a diferenciá-los dos setores profissionais, ou seja, aqueles grupos mais qualificados, mais remunerados e, por isso mesmo, tendencialmente mais estáveis, da classe trabalhadora. Em suma, identificamos o precariado com a fração mais mal paga e explorada do proletariado urbano e dos trabalhadores agrícolas ${ }^{28}$.

\footnotetext{
${ }^{26}$ Kallemberg, 2009:25.

${ }^{27}$ Kallemberg, 2009:25, grifo nosso.

${ }^{28}$ Druck, 2011:19.
} 
Por fim, se os indígenas, de certo modo, sempre estiveram próximos do precariado, em função da política colonial, ao atingir o estrato profissional indigenista, o precariado se afasta de sua concepção original, prevista em Druck e avança em direção a uma categoria profissional que gozava de um ambiente de trabalho (até certo) ponto estável e gozava de certo status social até, pelo menos, antes da re-estruturação interna do órgão, amparada na seguridade conferida pela articulação territorial em zonas e redes, que constituíam as malhas de seus espaços vivido e percebido (ainda que só tenha visto sua remuneração se ampliar como medida pródesenvolvimentistas do período em estudo). A ruptura com este modelo territorial torna a precarização indigenista condizente com a proposição de Standing, que afirma que, em última instância, "todos estão caminhando para o precariado", para o emprego "sem estatuto" ou sem garantias contra eventuais episódios de violência e insegurança (Standing, 2013:97). Entende-se, assim, o que afirma Graça Druck, na epígrafe deste trabalho: "não há limites para a precarização".

\section{O indigenismo e seus espaços: conflito e representação}

Gostaria de retomar as ideias de Henri Lefebvre, desta vez sobre a dialética entre representação do espaço e espaços de representação. Até agora, de certo modo seguindo a tradição clássica da geografia, os geógrafos indigenistas tem se dedicado à estudo das representações do espaço, a "segunda natureza" que é o espaço indigenista clássicointegracionista, com sua configuração territorial estabelecida com o uso por meio de ferramentas, “expansões dos corpos" dos indígenas e por meio da forma indigenista, "próteses territoriais", "trabalho morto" que viabiliza a reprodução do modelo em zonas (TIs) e redes (unidades administrativas e operacionais).

Seu arranjo pode ser decomposto em ideologia (integração)/espaço normativo(jurisdição/administração)/modo de produção(capitalista). Com efeito, este arranjo é instrumentalizado pelo que Lefebvre chama de usuários do espaço: os agentes políticos e econômicos que detém o poder de estabelecer o ordenamento do território, através dos mecanismos de controle e coerção social, particularmente pelo domínio do instrumento arranjo normativo, num tipo de inscrição ou registro geográfico que orienta a existência em direção um ethos específico, ethos colonial, que confere legitimidade ao poder. Na outra mão deste arranjo espacial, encontram-se os usadores, aqueles que estão subordinados e re-existem ao controle. Para compreendê-los, deve-se buscar conhecer e apresentar o espaço no qual re-produzem sua existência. 
A cartografia de seus espaços revela que indígenas e indigenistas encontram-se diferentemente inseridos na lógica do arranjo espacial. Suas geograficidades, contudo, são determinadas pela representação indigenista, de modo que as alterações na estrutura do arranjo impactam de maneira decisiva a vida dos indígenas e seus espaços.

Segundo Ruy Moreira, o estudo do arranjo espacial é...

...fato de fundamental importância ao estudo da formação espacial e da (...) da formação econômico-social", chave da inserção da geografia e dos geógrafos no campo da teoria e prática da transformação social no sentido da resolução dos problemas mais candentes de nossa época, ao lado dos estudiosos sociais. (MOREIRA, 2008:23)

\section{Desencaixe do arranjo espacial e conflitividade}

As rupturas e conflitos no arranjo espacial indigenista e o "desencaixe" espaço-temporal remetem também à dialética entre o ser e o devir (Porto-Gonçalves, 2013), já que implicam também em rupturas na vida social destes sujeitos, iluminados pelo contexto global de expansão do precariado e sua multiplicidade processual (Standing, 2013; Antunes, 2008; Antunes \& Praun, 2011). Os sujeitos destacados neste trabalho (indígenas e indigenistas) vivenciam esse período de maneira intensa, nem sempre passivos ao acirramento dos conflitos de toda sorte que se instalaram, agravadas pelo próprio movimento de espacialização. A noção de "espacialização" ao interessante ponto de vista de Carlos Walter Porto Gonçalves ${ }^{29}$, que preconiza o entendimento da geografia não como um substantivo, mas como verbo. assim, dirante do elevado padrão de conflitividade observado no espaço percebido vislumbra-se um elevado padrão de conflitividade como uma das marcas das espacializações do período, reveladora das resistências e das lutas sociais concretas de indígenas e indigenistas ${ }^{30}$.

Analisando tal conjuntura, durante a Ação que julgou a demarcação da TI Raposa-Serra do Sol em 2009, o ministro Gilmar Mendes, concedeu voto contrário ao pleito dos produtores rurais que contestavam a demarcação contínua da Terra Indígena situada em Roraima. Mendes ressaltou que grande parte da crítica realizada pelos produtores rurais à FUNAI era devida, mas que isso não poderia vir a prejudicar o direito da coletividade indígena. Ao concluir seu voto,

\footnotetext{
${ }^{29}$ Porto-Gonçalves, 2003.

${ }^{30}$ Ver matéria: "Por 10 votos a 1 ministros definem demarcação contínua da Raposa Serra do Sol", G1 Notícias, 19/03/2009. Ver: http://g1.globo.com/Noticias/Brasil/0,MUL1050202-5598,00POR+VOTOS+A+MINISTROS+DO+STF+DEFINEM+DEMARCACAO+CONTINUA+DE+RESERVA.html.
} 
afirmou, de maneira célebre, que "os índios se encontram jogados à sua própria sorte, tal a dimensão do abandono e falta de rumos da política indigenista atual", algo que vinha até então sendo silenciado no ambiente indigenista por meio de coerções e perseguições, e, ao mesmo tempo, reveladora da desordem territorial que reinava no período. Em relação à Raposa, a decisão manteve os limites definidos pelos estudos técnicos realizados Fundação Nacional do Índio.

Por sua vez, os Atos Administrativos do período que mais causaram reações adversas da parte dos múltiplos sujeitos, além da PNGATI, já abordado, chama a atenção também a "reestruturação" da FUNAI, no ano de 2009, por meio do Decreto 1.056. Outros atos, no entanto, repercutiram fortemente na vida dos sujeitos indigenistas e nas mudanças do arranjo espacial, podem ser classificados em: a) Atos organizativos, que estabelecem normas de organização interna do indigenismo (Decreto 1.056/2009, que estabelece a "re-estruturação da FUNAI"; a PNGATI / 2012, que estabelece a Política Nacional de Gestão Ambiental e Territorial Indígena; a Portarias que estabelecem o Código de Ética Profissional Indigenista (2015) e a Portaria que estabelece os critérios para realização do turismo em Terras Indígenas (2015); b) Atos finalísticos, os que visam à demarcação de Terras Indígenas, bem como outras medidas diretamente voltadas à realização da finalidade indigenista, ou seja, diretamente voltados para os povos indígenas, com a ascensão do assistencialismo; c) Atos de pessoal, os quais dizem respeito aos atos voltados para a gestão de recursos humanos, dentre os quais atos que estabelecem: demissões, vacâncias, remoções (arbitrárias ou não), abertura de processos administrativos e nomeações (inclusive para cargos comissionados).

Quadro 1: Arranjo Jurídico-Normativo do Indigenismo no período 2007-2015.

\begin{tabular}{|cc|}
\hline $\begin{array}{c}\text { Estatuto do Índio } \\
\text { Lei 6001/1973 }\end{array}$ & $\begin{array}{c}\text { Classifica os povos indígenas } \\
\text { conforme o "grau" de integração }\end{array}$ \\
$\begin{array}{c}\text { Constituição Federal } \\
1988\end{array}$ & $\begin{array}{c}\text { Marco Jurídico, mas não temporal } \\
\text { Assegura o direito à diferença }\end{array}$ \\
$\begin{array}{c}\text { Decreto 1.056/2009 } \\
\text { Reestruturação da } \\
\text { FUNAI }\end{array}$ & Ruptura com o Rondonianismo \\
& "Profissionalização" do indigenismo \\
Decreto 7747/2012 & Hegemonia do Orgânico \\
Institui a PNGATI & Indigenismo "ambiental" \\
\hline
\end{tabular}

Fonte: Autor, 2019 
A partir destes atos pode-se vislumbrar as rupturas e rearranjos envolvem a política indigenista do período 2007-2015, evidenciando a precarização de seu arranjo territorial e suas repercussões diferenciadas na totalidade social. A resistência a alguns destes atos foi tão firme em alguns casos, o que motivou dezenas de processos judiciais ${ }^{31}$ e obrigou a recuos do Governo, com a revogação de determinados atos controversos. Chama atenção os casos de remoção arbitrária de servidores considerados oposicionistas, a transferência de sede das unidades administrativas. Muitos deles tiveram destaque na mídia nacional e internacional. Muitos outros, entretanto, não foram tocados, persistindo no horizonte de luta dos sujeitos sociais.

\section{Em busca de uma síntese}

Procurei abordar a precarização territorial contemporânea, observando sua relação direta com a acumulação flexível, excerto da crise do fordismo e do esfacelamento do estado de bem estar social (anos 1970), a partir de seus impactos para a política indigenista brasileira. Se à primeira vista parecia um processo indigenista em particular, agora está mais claro que trata-se de um processo global e multiforme, de onde decorre sua complexidade. A precarização territorial se depara com intensos processos de re-existência nos espaços sociais que (des)ordena, evocando o conflito e elevando o padrão de conflitividade dos sujeitos sociais, o que se dá imerso em contradições discursivas e confusão das lutas, não raro pela cooptação dos agentes políticos. Creio que o documento final da luta das mulheres indígenas,em que afirmam: "Território, nosso corpo, nosso espírito" seja o símbolo maior desta luta ${ }^{32}$.

Com efeito, a desordem territorial só se prenunciava no período 2007-2015. Com a ascensão de Jair Bolsonaro à presidência da república, um cenário obscuro se anuncia para os movimentos sociais em geral e também para os indígenas, enquanto prosperam atos jurídiconormativos que contemplam os interesses dos sujeitos sociais hegemônicos: o Estado, os capitais financeiro, monopolista e especulativo, como temos visto, em, com o desmonte da legislação trabalhista e dos direitos da população. Em relação ao indigenismo, chama atenção as constantes ameaças e ataques aos direitos indígenas, continuidade de nomeação de titulares cuja atuação é

\footnotetext{
31 "MPF-RO acusa ex-presidente da FUNAI de improbidade administrativa" (Página de notícias do MPF-RO, 31 de Julho de 2014).

${ }^{32}$ http://apib.info/2019/08/15/documento-final-marcha-das-mulheres-indigenas-territorio-nosso-corpo-nossoespirito/
} 
contrária ao interesse da maioria das comunidades indígenas, bem como a expansão da violência e dos conflitos nas aldeias e terras indígenas ${ }^{33}$.

O movimento da precarização, sob a égide da acumulação flexível, impõe a desordem para os sujeitos sociais concretos, observáveis no avanço de territorializações perversas. Tal é o caso da dinâmica territorial e das espacializações recentes do capitalismo brasileiro. Os projetos mais representativos do período aqui compreendido: as hidrelétricas de Belo Monte, Jirau, Madeira, foram totalmente construídas com a utilização de mão de obra precária e volante, incluindo mesmo o surgimento de uma nova categoria profissional: os barrageiros, operários da construção de hidrelétricas.

No mesmo período, um recuo na demarcação de Terras Indígenas e, mesmo, a redução de Unidades de Conservação já anteriormente estabelecidas, a fim de atender a projetos tidos como "prioritários" para o poder central (tal é o caso do Parque Natural dos Campos Amazônicos). É nesta esfera de atuação que se observa o conflito entre realidade e representação na análise da ação indigenista, já que, ao invés de defender o interesse dos indígenas, contrários a tais projetos, e ainda, com total reprovação dos indigenistas atuantes, a institução indigenista atuar em defesa do interesse das corporações, confrontando o Estado de Direito por meio de ações e coações.

Diante do que expus até aqui, gostaria de afirmar que a precarização do indigenismo enquanto política pública esboça uma ruptura incompleta com o arranjo territorial precedente, com recuos de cidadania para os sujeitos sociais envolvidos (indígenas e indigenistas), sobretudo porque seus logros políticos foram interrompidos abruptamente a partir de 2016. No entanto, durante o período 2007-2015, a política indigenista buscou mais que em qualquer outro momento o abandono das suas estruturas oligárquicas históricas. No entanto, esta não foi motivada por um movimento emancipatório, com a discussão de um projeto de autonomia para os Povos Indígenas como política de superação do Indigenismo, sobretudo de sua versão paternalista. Concomitante ao abandono das antigas e tradicionais lutas por terra, os direitos territoriais foram sutilmente pela agência indigenista em direção ao consumo (direitos sociais). Num momento em que o cotidiano destes indígenas restava, irreversivelmente, alienado pelo facão, o machado e a espingarda, o impacto da acumulação flexível sobre as visões de Estado faz com que os índios

\footnotetext{
${ }^{33}$ Ver dados em Cadernos dos Conflitos do Campo no Brasil, da Comissão Pastoral da Terra. Disponível em: https://www.cptnacional.org.br/publicacoes-2/destaque/4687-conflitos-no-campo-brasil-2018
} 
descubram que a FUNAI já não tem mais condições de atender, ad eternum, suas demandas por tais objetos. A situação de vulnerabilidade se confunde com a desterritorialização, já que, no trânsito entre os mundos da ancestralidade e a contingência/necessidade do facão, o indígena vivencia tanto uma territorialidade no trânsito, quanto uma multiplicidade de territórios e territorialidades distintas, ocupando em cada um, um lugar em particular.

Nota: Contribuíram direta ou indiretamente Janayara Lima, Marcio D’Arrochella, Flavia Elaine Santos, Marcio Pinon de Oliveira, Ruy Moreira, Carlos Walter Porto-Gonçalves, Rogério Haesbaert, Valter Cruz, Denilson Oliveira e Leandro Tartaglia, além de Fabiano Bringel, Willame Ribeiro e Aiala Couto.

\section{REFERENCIAS}

AMPARO, Sandoval dos Santos. Da Ordem Cósmica á Desordem territorial: A Geograficidade ameríndia no Chão de Abya Yala ou América Latina, Tese de Doutorado defendida junto ao Programa de Pesquisa e Pós-Graduação em Geografia da Universidade Federal Fluminense, Niterói, Junho de 2019.

ANTUNES, Ricardo. Adeus ao Trabalho? Ensaio sobre as metamorfoses e a centralidade do mundo do trabalho. 13 ${ }^{\mathrm{a}}$ ed. (revista e ampliada), Cortez Editora, São Paulo, 2008.

BLOEMER, Neusa Maria Sens \& NACKE, Anelise. “A precarização de políticas públicas e suas repercussões na auto-sustentação dos Kaingáng do oeste catarinense" in ILHA: Revista de Antropologia, N.15, V. 31 (81-102), Florianópolis, 2013.

BUTLER, Judith. Relatar a si mesmo: Crítica da violência ética, ( $2^{a}$ Reimp.) Editora Autêntica, Belo Horizonte, 2017. Trad. De Rogério Bettoni.

DRUCK, Graça. "Trabalho, precarização e resistências: novos e velhos desafios" in Caderno CRH, V. 24, N. 01 (especial, 37-57), Salvador, 2011.

DUTRA, Daline \& GOETTERT, Jones. "Precarização do trabalho: apontamentos a partir da mobilidade na fronteira Brasil-Paraguai” in $\mathbf{1 2}^{\mathbf{0}}$ Encuentro de Geógrafos da América Latina, Montevidéu - Uruguai, 2009.

FARIA, Camila Salles. A integração precária e a resistência na periferia da metrópole: os Guarani Mbya da aldeia Jaraguá. Dissertação de Mestrado em geografia, USP, 2008. 
HAESBAERT, Rogério. O mito da desterritorialização: do fim dos territórios à multiterritorialidade. $5^{\mathrm{a}}$ ed., Bertrand Brasil, Rio de Janeiro, 2010.

KALLEMBERG, Arne. "O crescimento do trabalho precário: um desafio global" in Revista Brasileira de Ciências Sociais, V. 24, N. 69, fevereiro de 2009.

LEFEBVRE, Henry. Elements de rythmanalyse: introduction à la connaissance des rythmes, Editions Syllepse, Paris,

LEFEBVRE, Henry. O direito à Cidade, Editora, Centauro, São Paulo, 2001.LIMA, Antonio Carlos de Souza, Um grande cerco de paz: poder, tutela, indianidade e formação do Estado no Brasil, Editora Vozes, Petrópolis, 1995.

LIMA, Antonio Carlos de Souza, Um grande cerco de paz: poder, tutela, indianidade e formação do Estado no Brasil, Editora Vozes, Petrópolis, 1995

MOREIRA, Ruy. Pensar e ser em Geografia. São Paulo: Contexto, 2007.

OLIVEIRA, João Pacheco de. \& LIMA, Antônio Carlos de Souza (Orgs.). Índios, militares e fronteiras: o projeto calha norte. Ed. UFRJ, Rio de Janeiro, 1990.

OLIVEIRA, João Pacheco de (org.). Indigenismo e Territorialização: Poderes, Rotinas e Saberes Coloniais no Brasil Contemporâneo. Ed. Contra Capa Livraria, Rio de Janeiro, 2008. POLANCO, Hector Diaz. "Los dilemas del pluralismo". In: Pueblos Indígenas, Estado y Democracia (p. 43-66), CLACSO - Consejo Latinoamericano de Ciencias Sociales, Buenos Aires, 2005.

PORTO-GONÇALVES, Carlos Walter. “A geograficidade do social: uma contribuição para o debate metodológico sobre estudos de conflito e movimentos sociais na América Latina" in SEOANE, J. (Org.), Movimientos Sociales y conflitos em América Latina, CLACSO, Buenos Aires, 2013.

PORTO-GONÇALVES, Carlos Walter \& HAESBAERT, Rogério. A nova desordem mundial, Editora UNESP, São Paulo, 2006.

SANTOS, M. Metamorfoses do espaço habitado. EdUSP/HUCITEC, São Paulo, 2003.

SÁ, Teresa. "Precariedade e Trabalho precário: consequências sociais da precarização laboral" in Configurações Revue, N. 7 Lisboa, 2010.

SINGER, André. Os sentidos do Lulismo: reforma gradual e pacto conservador. Ed. Companhia das Letras, Rio de Janeiro, 2012. 